Maria Inês Reinert Azambuja 1 Bruce B. Duncan 1

\section{Similarities in mortality patterns from influenza in the first half of the 20th century and the rise and fall of ischemic heart disease in the United States: a new hypothesis concerning the coronary heart disease epidemic}

\author{
Semelhanças entre o padrão de mortalidade \\ por influenza na primeira metade do século $X X$ \\ e o padrão de mortalidade por doença isquêmica \\ do coração no transcorrer do século, nos Estados \\ Unidos: uma nova hipótese para a epidemia \\ de cardiopatia isquêmica
}

\footnotetext{
1 Departamento de Medicina Social, Faculdade de Medicina, Universidade Federal do Rio Grande do Sul. Rua Ramiro Barcel os 2600 40 andar, Porto Al egre, RS 90035-003, Brazil. miazambuja@via-rs.net
}

Abstract The classic risk factors for developing coronary heart disease (CHD) explain less than $50 \%$ of the decrease in mortality observed since 1950 . The transition currently under way, from the degenerative to the infectious-inflammatory paradigm, requires a new causal interpretation of temporal trends. The following is an ecological study based on data from the United States showing that in men and women an association between the age distribution of mortality due to influenza and pneumonia (I\&P) associated with the influenza pandemic in 1918-1919 in the 1049-year age bracket and the distribution of CHD mortality from 1920 to 1985 in survivors from the corresponding birth cohorts. It further shows a significant negative correlation $(r=-0.68, p=$ 0.042) between excess mortality from I \&P accumulated in epi demics from 1931 to 1940 (used as indicator for persistent circulation of $\mathrm{H} 1 \mathrm{~N} 1$ virus combined with vulnerability to infection) and the order of the beginning in the decline in CHD mortality in nine geographic divisions in the United States. In light of current biological knowledge, the data suggest that the 1918 influenza pandemic and the subsequent epidemics up to $1957 \mathrm{might}$ have played a determinant role in the epidemic of CHD mortality registered in the 20th century.

Key words Mortality; Myocardial Ischemia; Influenza; Pneumonia

Resumo Os fatores de risco clássi cos para o desenvolvimento de doença isquêmica do coração (DIC) explicam menos de 50\% da queda na mortalidade observada desde 1950. A transi ção em curso, do paradigma degenerati vo para o inflamatório/infeccioso, requer nova interpretação causal das ten dências temporais. Este é um estudo ecológico, baseado em dados dos Estados Unidos, que mostra, em homens e mulheres, uma associação entre a di stribui ção etária da mortali dade por influenza e pneumonia (I\&P) associada à pandemia de influenza de 1918-1919 na faixa dos 10 aos 49 anos e a distribui ção da mortalidade por DIC, entre 1920 e 1985, em sobreviventes das coortes de nascimento correspondentes. Mostra ainda uma correlação negativa si gnificativa ( $r=-0,68, p=0,042)$ entre o excesso de mortalidade por I\&P acumulado em epidemias entre 1931-1940 (utilizado como indicador da persistência da circulação de vírus H1N1 aliada à vulnerabilidade à infecção) ea ordem do início do declínio na mortalidade por DIC, em nove divisões geográficas dos Estados Unidos. Os dados sugerem, à luz do conheci mento bi ológico atual, quea pandemia de influenza de 1918 e as que se seguiram até 1957, pudesse ter tido papel determinante na epi demia de mortalidade por DIC registrada no sécul o XX.

Palavras-chave Mortalidade; Isquemia Miocárdica; Influenza; Pneumonia 
In the course of the last 70 years, a rise and fall in mortality from coronary heart disease (CHD) occurred in several countries. In the United States, angina emerged as a significant cause of death in the mid-1920s (Stallones, 1980). From then on, CHD mortality rose steadily until the early 1960s, when it leveled off at around 35\% of overall mortality (Havlick \& Feinleib, 1979). The decline began in 1968 and accelerated after 1972 (Levi, 1981), resulting in a fall of more than $40 \%$ in CHD death rates in the last 30 years (Sytkowski et al., 1996).

The CHD mortality time trend has still not been explained satisfactorily (Metha et al., 1998), with traditional risk factors accounting for less than $50 \%$ of the variation in rates registered since 1950 (Sytkowski et al., 1996). As stated by Mizgala $\&$ Shulzer (2000), the results of the MONICA study and the disappointing results of primary intervention trials based on those risk factors suggest that "it is perhapstime to recognize the possibility that trends in CHD mortality seen across the world in the past 30 years or so, may be driven by forces independent of the classic risk factors" (Ebrahim \& DaveySmith, 1999, apud Mizgala \& Shulzer, 2000:430).

Since the late 1970s, evidence provided by experimental and clinical studies (Koenig et al., 1999; Kol \& Libby, 1999; Lindberg et al., 1992; Ridker et al., 1997; Ross, 1999; Schmitz et al., 1998) has challenged the traditional notion of CHD as a degenerative condition, supporting instead an alternative view of CHD as an immune inflammatory disease (Metha et al., 1998; Schmitz et al., 1998; Watanabe et al., 1996). Several authors have also postulated a role for infection in initiation and/or progression of CHD and risk of myocardial infarction or death (Hajjar et al., 1986; Kol \& Libby, 1999; Nieto, 1998; Zhu et al., 2001). However, thus far few attempts have been made (Anestad et al., 1997; Mozar et al., 1990) to incorporate the infectious-inflammatory hypothesis into explanations for 20th-century CHD mortality trends.

The degenerative paradigm has attempted to explain the CHD epidemic as secondary to time-trend variation in exposures to risk factors for development of disease. An infectious-inflammatory hypothesis would support a somewhat different explanation, that is, one based more on a variation in individual susceptibility to CHD over time.

It has been shown that certain infections affect an individual's response to subsequent infections (Griffin, 1994) as well as to other environmental challenges (Evans \& Brachman, 1986), among them being high-fat diets (Hajjar et al., 1986). Thus, theoretically, a massive occur- rence of an infectious disease could have led to the emergence of the CHD epidemic, even if other environmental exposures (e.g.: high fat intake, smoking) had not changed over time, by modifying individuals' susceptibility to their effects.

A major worldwide infectious event immediately preceding the rise in CHD mortality was the 1918 influenza pandemic. Twenty-five percent of the US population (at least 25 million people) had overt flu during that pandemic, resulting in at least 500,000 excess influenza and pneumonia deaths (Crosby, 1989). Worldwide, the minimum estimated mortality was $21 \mathrm{mil}$ lion people, with the real number easily reaching 30 to 40 million (Crosby, 1989).

Influenza viruses circulating from 1918 to 1957 maintained an important overlap in terms of serological and biochemical laboratory tests, ecology, and public health effects, and are now all classified in the HIN 1 subtype of influenza A viruses (Dowdle, 1999). Could the pathogenetic burden of H1N 1 influenza infection on the US population explain the observed epidemiological pattern in 20th-century CHD mortality?

\section{H1N1 influenza in the United States}

The Spanish flu of 1918 had unique characteristics compared to the 1958 (H2N2 sub-type) and 1968 (H3N2 sub-type) influenza pandemics (Crosby, 1989; Dowdle, 1999): (1) unusually high morbidity and mortality; (2) high male/ female and white/ black morbidity and mortality ratios; and, oddly, (3) highest morbidity and mortality burden among young adults.

As shown in Figure 1 (Collins, 1930; Crosby, 1989; US Bureau of the Census, 1955), the incidence of respiratory illnesses (with at least one day in bed) peaked in both sexes at age 10, followed by a drop in the twenties, a second peak during the thirties, and a significant fall in the forties. However, one-third to one-half of deaths were concentrated in the second and third decades of life. The consensus of the American Public Health Conference of December 1918 was that the most frequent victims of flu were "those who had been in the best of physical condition and freest from previous di sease" (Crosby, 1989: 216). According to expert opinion, death was due not to direct viral damage but to the strength of the immune-inflammatory response to infection, greater in robust young (white, male) adults (Crosby, 1989).

We thus hypothesize that whatever immuneinflammatory mechanism caused a sex and age mortality pattern in 1918-1919 which differed from that of incidence of respiratory symptoms 


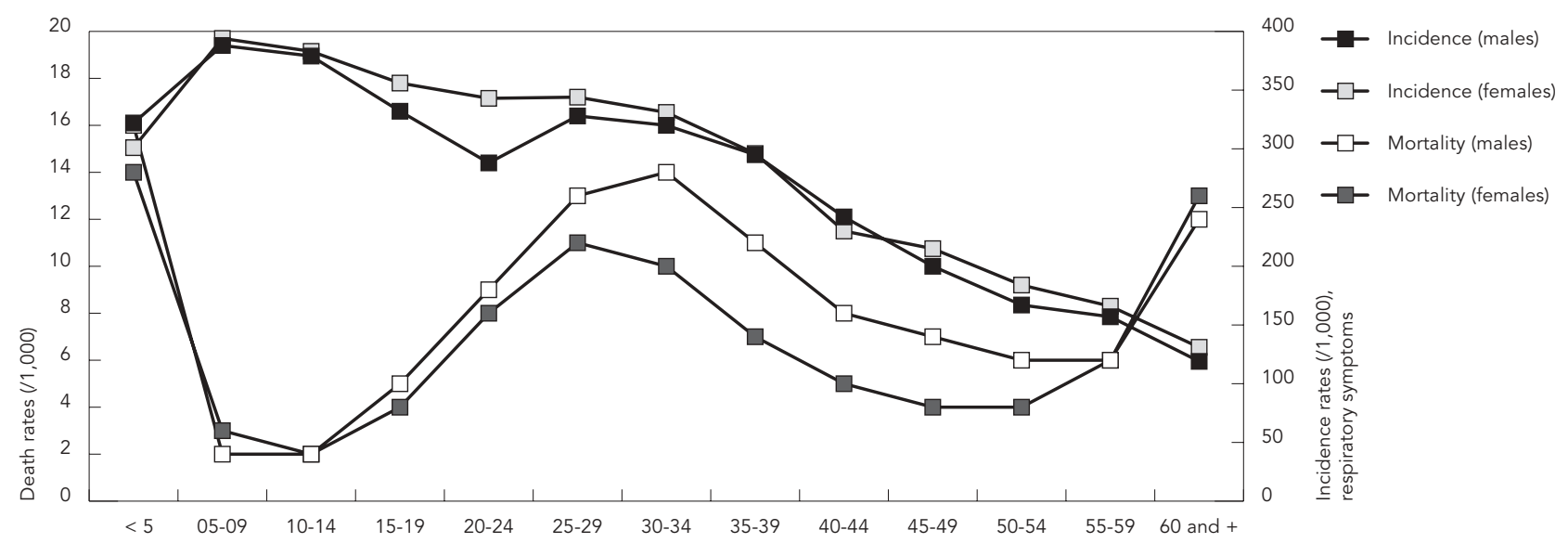

Source: Collins (1930); Crosby (1989); US Bureau of the Census (1955).

during the pandemic (see Figure 1 ) also "primed" survivors in a similar fashion, predisposing them to future development of CHD. If that were the case, then the relative distribution of influenza-related deaths among individuals ages 15 to 49 in 1918-1919 (a proxy for the distribution of some particular kind of immune-inflammatory response to infection across the range of exposed birth cohorts) should predict the occurrence of CHD mortality in survivors from the corresponding birth cohorts (from about 1870 to 1915) in the subsequent years. (The higher 1918-1919 influenza and pneumonia mortality at the extremes of life is presumably related to other mechanisms, irrelevant to the hypothesis discussed here, as influenza epidemics usually present greater mortality at the extremes of life.)

While flu activity showed a continuing decline from 1918 to 1957, such a trend was not uniform across the United States (Collins, 1930; Gover, 1943). Thus we further hypothesize that the reported geographic variation in time of onset of the decline in CHD death rates depended on the varying persistence of $\mathrm{H} 1 \mathrm{~N} 1$ viruses across the United States, and, through their effect, on a lower level but continuing CHD “initiation" taking place in later birth cohorts.

\section{Methodology}

This paper presents ecological associations between influenza and CHD occurrences across birth cohorts and across geographic areas of the United States, in support of the two hypotheses presented above.

\section{Birth cohort correlation}

United States gender- and age-specific mortality data were used to graphically compare the burden of the 1918-1919 influenza pandemic with that of the 1920-1985 CHD epidemic across birth cohorts.

\section{Influenza data}

Sex and age strata-specific influenza mortality rates were calculated using the number of deaths from influenza and pneumonia in 1918 (Crosby, 1989) and an estimate of the population residing in the US Registration Area for 1917 (US Bureau of the Census, 1955) used at that time for national tabulations of vital events and covering approximately $80 \%$ of the US continental population (Collins, 1930). Deaths occurring during 1918 and 1919 were assigned to January 1, 1919. They were then adjusted to reflect the age the deceased would have had in 1920 , so that the age-specific rates could be plotted for birth cohorts according to the usual center of 10-year birth cohort intervals (July 1 of years ending with 0 or 5). Since one and a half years elapsed between January 1, 1919, and July 1, 1920, this adjustment was performed for each age stratum, adding, in weight- 
ed fashion, the 1918-1919 influenza and pneumonia stratum-specific death coefficient of the age stratum in question (weight $=0.85$ ) to the death coefficient of the next youngest stratum (weight $=0.15$ ).

\section{CHD mortality data}

For the most recent period, 1960-1985, CHD mortality rates were calculated based on gender- and age-specific data (number of deaths and population) referent to the total US population (all races), obtained from the Division of Vital Statistics of the National Center for Health Statistics (NCHS, 1990). Age-specific CHD mortality was defined as the number of deaths classified according to the International Classification of Diseases (ICD) revision effective in the year of death, divided by total population in the same year, in each 10-year stratum. ICD versions prior to 1950 were too variable in their definitions of heart disease to characterize, in a standardized way, the US CHD death trends (Coulson, 1975). Thus, to document birth-cohort trends during the ascendant limb of the CHD epidemic curve, we used published tables on the number of deaths ascribed to coronary heart disease (and population), by age and sex referent to Seattle-King County (State of Washington) only (Ravenholdt, 1966). In this subset of data, the assigned cause of death resulted from a review and tabulation of all death certificates registered in that area from 1920-1960, at every fifth year, in accordance with the 1955 international standards (ICD-7). Using both sets of data, we tabulated CHD mortality according to 10-year age and birth cohort strata. To make the total CHD mortality burden comparable across different distributions of age in successive birth cohorts, we defined, separateIy for men and women, a referent birth cohort having a mid-period number of survivors at each successive 10-year age interval (from ages 40-49 to $80+$ ) equal to the number of individuals at the respective 10-year age strata of the 1940 US total population (US Bureau of the Census, 1954). We then estimated age strataspecific standardized numbers of CHD deaths for successive birth cohorts by multiplying the age stratum-specific death rate corresponding to each specific birth cohort by the number of individuals estimated at mid-period in the respective 10 year age stratum in this standard population. Next, we calculated the total period age strata-specific standardized numbers of deaths, multiplying this mid-period number of deaths by 10 . In doing so, we extrapolate a oneyear mortality experience to that of a 10 -year period of observation of the cohort members as they pass through the specified 10-year age interval. Finally, we graphically summed the age strata-specific standardized numbers of deaths within each birth cohort in order to obtain a standardized estimate of the total CHD mortality burden for each 10-year birth cohort.

\section{Geographic correlation}

We used the Spearman correlation coefficient to quantify the association, across the US geographic divisions, between longer persistence of HIN1 influenza viruses, estimated by total excess death rate from influenza and pneumonia measured during the whole of each epidemic occurring from 1931-1940 (Gover, 1943) and delayed onset of decline in CHD death rates estimated by the proportion of Metropolitan State Economic Areas in which the decline in CHD mortality had al ready begun in 1968, as analyzed by Wing et al. (1986).

\section{Results}

\section{Birth-cohort trends}

Figure 2 graphically compares the relative mortality associated with the 1918-1919 pandemic with that from the CHD epidemic in the period 1920-1985 across successive birth cohorts, separately for men and women. The solid line connects points representing the distribution of mortality from influenza and pneumonia in 1918-1919 for birth cohorts roughly corresponding to those with 10-50 years of age in 1918-1919 (see Figure 1). The vertical bars display the standardized number of CHD deaths, shaded to represent deaths in different age strata, among those same birth cohorts. As can be seen, for both sexes, for cohorts born in the last third of the nineteenth century, as pandemicrelated mortality increases so does the observed CHD mortality. Both distributions attain their peak in cohorts born just before 1900 and then begin to fall towards the latter-born cohorts. In cohorts born successively after 1900, a growing excess of observed CHD mortality in relation to that expected, in relative terms, from the pandemic mortality curve, can be seen, with this excess being somewhat larger for men.

\section{Geographic variability in onset of CHD decline}

As can be seen in Figure 3, after 1930, H1N1 influenza-related excess deaths varied consider- 
Relative distributions of 1918-1919 influenza and pneumonia death rates (line) and of 1920-1985 CHD standardizeda number of deaths by age (bars) in successive birth cohorts, according to age and sex, United States.
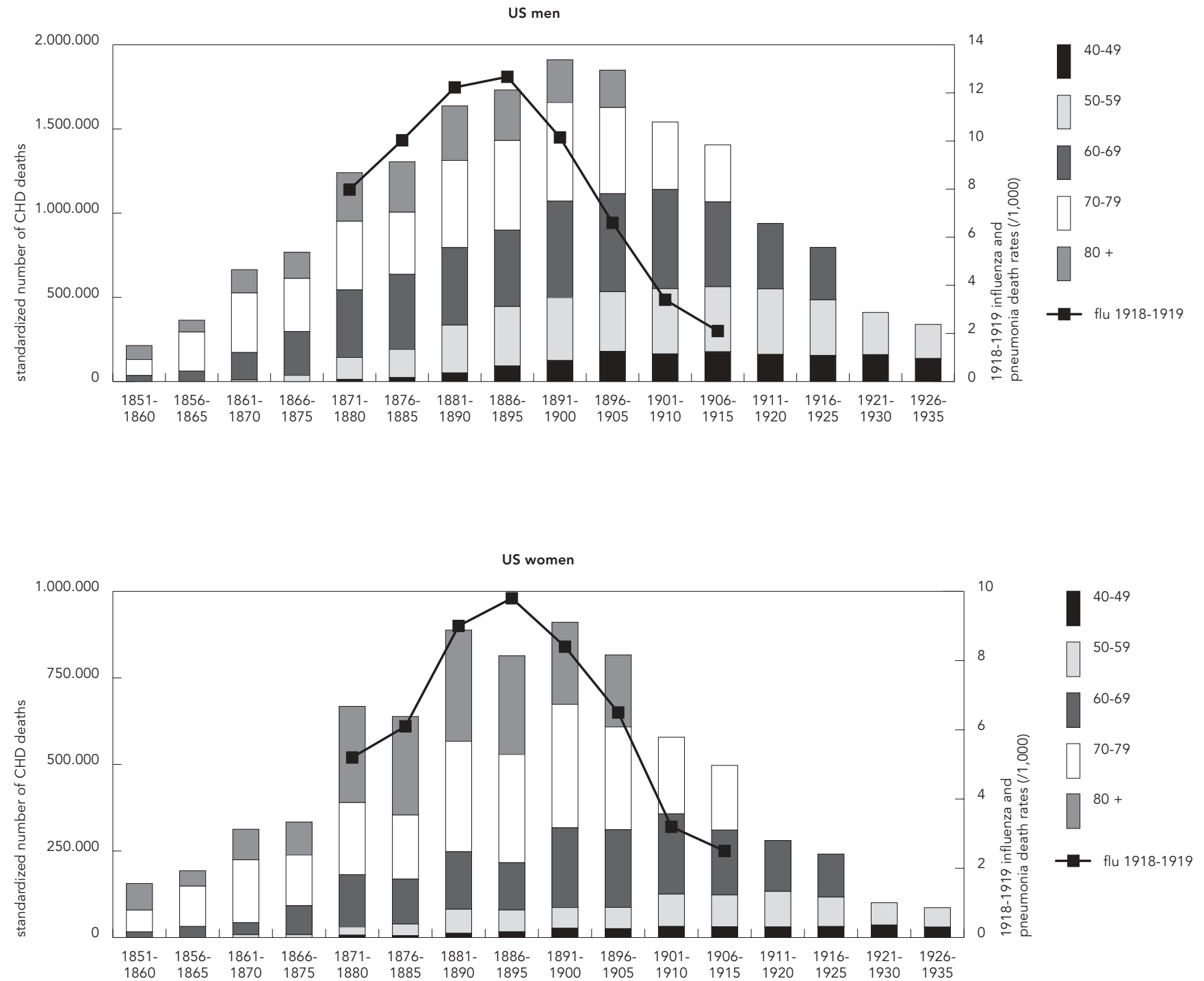

Sources: CHD mortality data from National Center for Health Statistics, Vital Statistics of the United States, Vol. II, Mortality. Published and Unpublished Data - Selected Years and US Bureau of the Census (1954). Influenza data from Crosby (1989) and US Bureau of the Census (1955).

a Standard population: 1940 US population, by sex and age strata.

ably across the US Geographic Divisions, being less in the Northeast, Mid-Atlantic, East North Central, South Atlantic, and Pacific Divisions compared to the West North Central, East South Central, West South Central, and Mountain Divisions. The onset of decline in CHD mortality also varied considerably, having begun in $100 \%$ of the Northeast and $98.5 \%$ of the
Pacific Metropolitan State Economic Areas in 1968 , but in only approximately $60 \%$ of Metropolitan Areas of the West North Central and East South Central Divisions.

A notable negative correlation exists between excess influenza and pneumonia mortality after 1930 and early decline in CHD mortality across the United States $\left(r_{S}=-0.68 ; p=0.042\right)$. 
Figure 3

Correlationa between persistence of $\mathrm{H} 1$ influenza activity after 1930 (measured by 1931-1940 influenza excess death rates - Gover, 1943) and timing of the onset of the decline in CHD mortality (measured by proportion of metropolitan SEAb with declining CHD death rates in 1968 and earlier, Wing et al., 1992) across the US Geographic Divisionsc.

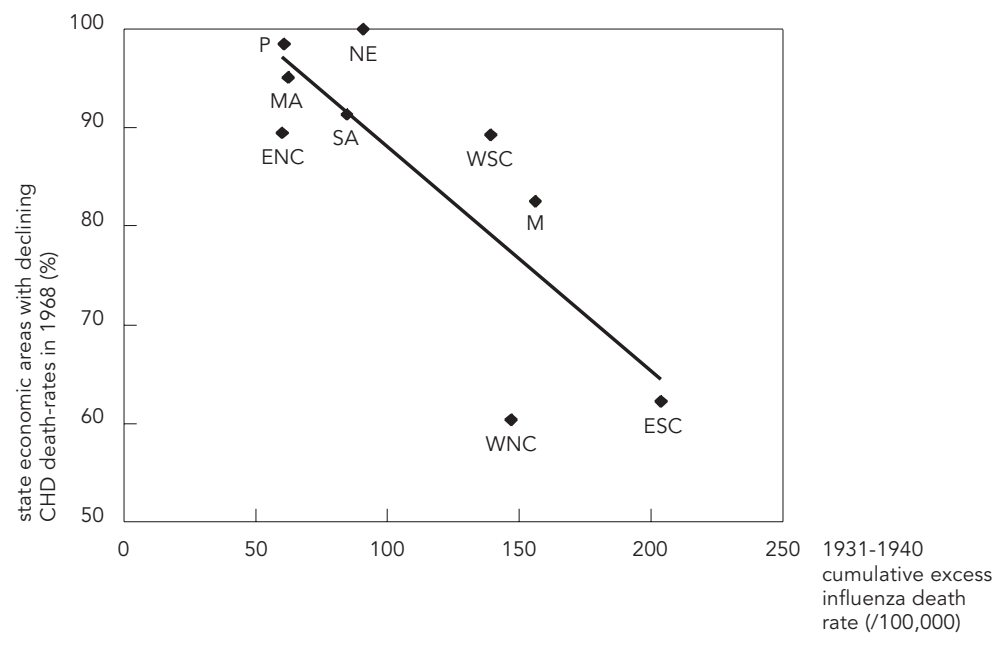

a Spearman (rs) correlation.

b SEA = State Economic Areas

c $\mathrm{NE}=$ Northeast; $\mathrm{P}=$ Pacific; $\mathrm{MA}=$ Mid-Atlantic; $\mathrm{ENC}=$ East North Central;

$\mathrm{SA}=$ South Atlantic; $\mathrm{WSC}=$ West South Central; $\mathrm{M}=$ Mountain;

WNC = West North Central; ESC = East South Central.

\section{Discussion}

The above data demonstrate two epidemiologically important ecological associations between the burden of HIN 1 influenza infection on the US population in the early 20th century and the mid-century rise in CHD mortality. Age-related influenza and pneumonia mortality during the 1918-1919 pandemic predicts well, separately in men and women, the relative distribution of CHD mortality across the corresponding birth cohorts. The burden of H1N 1 influenza activity post-1930, measured by influenza and pneumonia death rates, showed a strong association with delayed declines in CHD mortality across US Geographic Divisions. In fact, it might help explain the observed persistence of CHD mortality across the latest-born cohorts beyond that expected on the basis of an estimate which considered the 1918-1919 pandemic alone (see Figure 2).

Additionally, there are important socio-demographic similarities between those most affected by the 1918-1919 influenza and those who died from CHD. CHD mortality was al ways higher in men than women (Stallones, 1980). Male/ female death ratios during the pandemic also varied from 1.2 at ages $10-19$ to 1.7 at ages 40-49 (Crosby, 1989) (see Figure 1). CHD mortality was higher in whites than in blacks from the mid-1920s until about 1963, when a crossover in death rates occurred (Gillium, 1982). As mentioned, one of the unique characteristics of the 1918 pandemic was its unexpectedly high white/ black mortality ratio. Not only was mortality from influenza and pneumonia lower in blacks but, during the pandemic, "death-rates for all causes of blacks between 25 and 45 years of age were bel ow those of their white counterparts, probably for the only time in the history of the nation" (Crosby, 1989:229).

As flu epidemics disappeared from the Northeast and Pacific regions and influenza mortality decreased and became more localized in the Mountain and Southern regions of the country, (1) specific demographic characteristics of those populations (on average with a higher proportion of blacks compared to the Northeast and Pacific), (2) higher variability in rates of exposure (due to lower levels of circulating virus), and (3) differential susceptibility to HIN 1 infection across social strata (as demonstrated by Sydenstriker, 1931) could explain the Eastern/Southern (Stallones, 1980), white/ black (Gillium, 1982), and socioeconomic (Wing et al., 1992) crossovers in CHD mortality rates registered during the decline. The decline and more recent leveling off (Rosamond et al., 1998) in CHD incidence is consistent with progressive exhaustion of the influenza-priming effect within the surviving population.

Thus, these epidemiological findings support our hypothesis that gender, race, age, and geographic differentials in the burden of pathogenic effects due to H1N 1 influenza infection in the US population could help explain the main epidemiological characteristics (gender, race, birth cohort, and geographic pattern) of the 20th century CHD mortality epidemic.

\section{Speculations on pathogenic mechanisms involved in an influenza/CHD mortality association}

\section{Epidemiological clues}

The proportion of excess deaths occurring during influenza epidemics attributed to organic heart diseases grew considerably during the ascending phase of the CHD epidemic, from $1.6 \%$ in $1918-1919$ to $18.4 \%$ in the minor epidemics occurring during 1920-1929 (Collins, 
1932), and to $51 \%$ (cardiovascular-renal causes) of a total of 86,000 excess deaths registered during the 1957-1960 Asian influenza epidemics (Eickoff et al., 1961).

Beginning in the 1960s, a continuing improvement in survivorship, reflecting mostly a declining recurrence of myocardial infarction subsequent to initial diagnosis, was documented (Elveback, 1979). Although improved survivorship has usually been attributed to improved medical care, a change in disease/ host relationship over time has been considered a possibility (McKinley et al., 1989). As first suggested by Gordon \& Thom (1975), the reduction in death rates from CHD could be partially attributable to the continuing decline in influenza activity and the absence of extensive influenza epidemics after 1968. If the hypothesis proposed here is correct, reduction in repeat exposure of H1N 1 "primed" individuals to subsequent influenza infections might have been the determining factor in the change in disease-host relationship regarding CHD progression and death.

It is worth noting that historical records indicate the possible occurrence of a previous rise and fall in CHD mortality in Britain over the last third of the eighteenth century (Azambuja, 1995). Heberden's original description of the anginal syndrome in 1772, a time when its cardiac origin had not yet been established, followed a period of significant influenza activity in Britain, with epidemics recorded in 1727, 1732, 1737, and 1760 (Crosby, 1989).

\section{Clinical/pathological clues}

Sudden death was a hallmark of the CHD epidemic, especially during its ascending phase. According to McKinlay et al. (1989), at the height of the CHD epidemic, almost two-thirds of CHD deaths were sudden and unexpected and occurred outsi de hospitals, mostly as a result of acute arrhythmias. During the decline, this component of CHD mortality fell more dramatically than did incidence of acute myocardial infarction or long-term post-MI mortality (McKinlay et al., 1989). Sudden death was also a common component of cardiovascular deaths in influenza epidemics (Oseasohn et al., 1959), and it has recently been shown that influenza vaccination confers protection against sudden death (Siscovick et al., 2000). Obstruction of arteries supplying the conduction system of the heart (first septal artery, sinus node artery, atrioventricular node artery, posterior descending artery) is a preponderant finding among patients with sudden cardiac death, compared to apparently healthy subjects dying of accidental causes (Velican et al., 1989).

During the 1918 influenza pandemic, the most frequently observed circulatory disturbance was bradycardia. Particularly during convalescence, bradycardia often became marked. A small group of patients showed arrhythmias with either atrial or ventricular extrasystoles and conduction disorders, varying from simple prolonged P-R interval to bradycardia with "escaped sino-nodal beats", partial block (1:2, 1:3; 1:4), and complete heart block. Such effects on the heart were transitory and non-responsive to atropine. At autopsy, some dilatation of the right side was commonly observed, with diffuse changes such as "cloudy swelling", evidence of "parenchymal degeneration", loss of striation, but usually no clear-cut inflammatory changes of the myocardium (Anonymous, 1958). Endothelial cells were not described. However, infection and inflammation of arteries supplying the conduction system of the heart could explain both arrhythmias during the 1918 pandemic and sudden CHD deaths occurring during decades of relatively high influenza activity. Cytomegalovirus and influenza virus are capable of modulating the in vitro production of IL- 6 by human endothelial cells (Visseren et al., 1999). And the highly pathogenic avian influenza virus A/FPV/ Rostock/ 34 (H7N1) was shown to be highly endotheliotropic (Feldman et al., 2000).

\section{Biomolecular clues}

Infection by one strain of influenza A virus focuses the antibody (and possibly the T-cell) (Klenerman \& Zinkernagel, 1998) response to infections by different subsequent strains of influenza viruses on epitopes shared by the original hemagglutinin antigens, a process known as "original antigenic sin" (Dowdle, 1999; Hennessy \& Daven port, 1958). Similar to reactivation of rheumatic heart disease upon reinfection by group A beta-hemolytic streptococcus (Guilherme et al., 2001) and exacerbations of multiple sclerosis following viral-like infections (Fujinami, 2001), immune responses elicited at each new encounter with an influenza virus could reactivate inflammatory pathways to CHD, originally established by a first encounter with a HIN 1 influenza virus and some specific immune response to it. In this regard, atherosclerotic lesions are mostly located in areas which would logically receive the highest loads of both viruses and immunoinflammatory products from the infected lungs: the left side of the heart, the coronary arteries, and the aortic arch with its main branches. 
Besides a reinfection-driven autoimmune reactivation of endothelial inflammation leading to acute CHD events and/ or chronic progression of vascular disease, another possibility must also be considered: that flu infection or the immune response to it interfered with lipid metabolism, leading to increased susceptibility to high serum cholesterol levels. Pleskov et al. (1994) described, in some strains of influenza viruses, a significant mimicry of the amino acid sequences involved in cell attachment of the viral hemagglutinin with those of apolipoprotein $B$ involved in LDL binding to high-affinity LDL receptors. Upon reinfection, co-localization of anti-apo $B$ antibodies at sites of viral penetration in the vascular bed could result in intimal LDL accumulation followed by oxidation and subsequent foam cell formation (Steinberg \& Witzum, 1990)

Though speculative, a mechanism involving cross-reactivity between the $\mathrm{H} 1 \mathrm{~N} 1$ influenza strains and apoB-LDL or the LDL receptor could be a link from infection to hypercholesterolemia and CHD mortality and shed new light on the "diet-heart" controversy (Blackburn \& Jacobs, 1984). Within populations, the effect of dietary fat/cholesterol intake on serum cholesterol levels might depend more on the efficiency of LDL uptake, the latter possibly influenced by a cross-reactive immune response to a previous $\mathrm{H} 1 \mathrm{~N} 1$ influenza infection.

In short, although biological links between influenza and CHD remain to be proven, intriguing leads do exist.

\section{Conclusions and final remarks}

Ecological studies are weak designs to establish causality. However, the strength and consistency of the several different ecological correlates shown here, coupled with a potential biological plausibility of this epidemiologically-driven hypothesis within an immune-inflammatory paradigm of atherosclerosis, do make the associations presented worthy of further consideration.

Current evidence demonstrates that the diet-heart paradigm, which gave support to most of the research and intervention policies related to CHD during the 20th century, cannot adequately explain all the features related to the CHD time trends (Kuulasmaa et al., 2000; Metha et al., 1998; Mizgala \& Shulzer, 2000; Taubes, 2001). Since the 1990s, several other diseases traditionally associated with degeneration were shown to have, instead, an inflammatory basis and an infectious etiology (Lorber, 1996). Inflammation has also become the main paradigm of CHD pathogenesis, since Ross \& Glomset (1976a; 1976b) first demonstrated its dominant role in atherogenesis (Ross, 1999). We hope that this study, which expands previously presented (Reinert-Azambuja, 1994) evidence for the influenza/CHD epidemic hypothesis, will stimulate further investigation of influenza's role in the 20th-century course of CHD, permitting extension of the inflammatory paradigm and introduction of the infectious hypothesis to the interpretation of the rise and fall in CHD mortality, a worldwide occurrence described by the WHO (1969, apud Gordon \& Kannel: 1617) as "thegreatest epidemic mankind has faced".

\section{References}

ANESTAD, G.; SCHEEL, O. \& HUNGNES, O., 1997. Chronic infections and coronary heart disease. Lancet, 350:1028-1029.

ANONYM OUS, 1958. Cardiac disturbances during the pandemic of influenza of 1918 to 1920. Annals of Internal Medicine, 49:1267-1272.

AZAMBUJA, M. I., 1995. Rise and fall in ischemic heart disease mortality: It may have happened before. Revista de Saúde Publica, 29:440-443.

BLACKBURN, H. \&JACOBS, D., 1984. Sources of the diet-heart controversy: Confusion over population versus individual correlations. Circulation, 70:775-780 
COLLINS, S. D., 1930. Influenza-pneumonia mortality in a group of about 95 cities in the United States. Public Health Reports, 54:361-407.

COLLINS, S. D., 1931. Age and sex incidence of influenza and pneumonia morbidity and mortality in the epidemic of 1928-29 with comparative data for the epidemic of 1918-19. Public Health Reports, 46:1909-1937.

COLLINS, S. D., 1932. Excess mortality from causes other than influenza and pneumonia during influenza epidemics. Public Health Reports, 47:21592179.

COULSON, A. H., 1975. Fashions and Shrouds: TheInternational List Through Eight Revisions. Albany: Society for Epidemiologic Research. (mimeo).

CROSBY, A. W., 1989. America's Forgotten Pandemic: The Influenza of 1918. 1st Ed. New York: Cambridge University Press.

DOWDLE, W. R., 1999. Influenza A recycling revisited. Bulletin of theWorld Health Organization, 77:820828.

EICKOFF, T. C.; SHERM AN, I. L. \& SERFLING, R. E., 1961. Observations on excess mortality associated with epidemic influenza. JAMA, 176:776-782.

ELVEBACK, L., 1979. Coronary heart disease in Rochester, Minnesota, 1950-75: Incidence and survivorship. In: Proceedings of the Conference on the Decline in Coronary Heart Disease Mortality, 1978 (R. J. Havlick \& M. Feinleib, ed.), pp. 116123, Hyattsville: National Heart, Lung and Blood Institute, National Institutes of Health/Bethesda: US Department of Health, Education, and Welfare.

EVANS, A. S. \& BRACHMAN, P. S., 1986. Emerging issues in infectious diseases epidemiology. Journal of Chronic Diseases, 39:1105-1124.

FELDMANN, A.; SCHAFER, M. K.; GARTEN, W. \& KLENK, H. D., 2000. Targeted infection of endothelial cells by avian influenza virus A/FPV/ Rostock/34 (H7N1) in chicken embryos. Journal of Virology, 74:8018-8027.

FUJINAMI, R. S., 2001. Can virus infections trigger autoimmune disease? Journal of Autoimmunity, 16:229-234.

GILLIUM, R. F., 1982. Coronary heart disease in black population. American Heart Journal, 104:839-851.

GORDON, T. \& KANNEL, W. B., 1971. Premature mortality from coronary heart disease. The Framingham heart study. JAMA, 215:1617-1625.

GORDON, T. \& THOM, T., 1975. The recent decrease in CHD mortality. Preventive Medicine, 4:115-125.

GOVER, M., 1943. Influenza and pneumonia mortality in a group of 90 cities in the United States, August 1935-March 1943, with a summary for August 1920-March. Public Health Reports, 58:10331061.

GRIFFIN, D. E.; WARD, B. J. \& ESOLEN, L. M., 1994. Pathogenesis of measles virus infection: An hypothesis for altered immune response. Journal of Infectious Diseases, 170(Sup. 1):S24-31.

GUILHERME, L.; CUNHA NETO, E.; TANAKA, A. C.; DULPHY, N. \& KALIL, J., 2001. Heart-directed autoimmunity: The case of rheumatic fever. Journal of Autoimmunity, 16:363-367.

HAJJAR, D. P.; FABRICANT, C. G.; MINICK, C. R. \& FABRICANT, J., 1986 Virus-induced atherosclerosis. Herpesvirus infection alters aortic cholesterol metabolism and accumulation. American Journal of Pathology, 122:62-70.

HAVLICK, R. J. \& FEINLEIB, M. (ed.), 1979. Proceedings of the Conference on the Decline in Coronary Heart Disease Mortality. 1978. Hyattsville: National Heart, Lung and Blood Institute, National Institutes of Health/Bethesda: US Department of Health, Education and Welfare.

HENNESSY, A. V. \& DAVENPORT, F. M., 1958. Epidemiologic implications of the distribution by age of antibody response to experimental influenza virus vaccines. Journal of Immunology, 80:114121.

KLENERM AN, P. \& ZINKERNAGEL, R. M., 1998. Original antigenic sin impairs cytotoxic $T$ lymphocyte responses to viruses bearing variant epitopes. $\mathrm{Na}$ ture, 394: 482-485.

KOENIG, W.; SUND, M.; FRÖHLICH, M.; FISHER, H. G.; LÖWEL, H.; DÖRING, A.; HUTCHINSON, W. L. \& PEPYS, M. B., 1999. C-reactive protein, a sensitive marker of inflammation, predicts future risk of coronary heart disease in initially healthy middle-aged men: Results from the MONICA (Monitoring Trends and Determinants in CardiovascuIar Disease) Augsburg Cohort Study, 1984-1992. Circulation, 99:237-242.

KOL, A. \& LIBBY, P., 1999. Molecular mediators of arterial inflammation: A role for microbial products. American Heart Journal, 138(Sup.):S450-S452.

KUULASMAA, K.; TUNSTALL-PEDOE, H.; DOBSON, A.; FORTMANN, S.; SANS, S.; TOLONEN, H.; EVANS, A.; FERRARIO, M. \& TUOMILEHTO, J., 2000. Estimation of contribution of changes in classic risk factors to trends in coronary-event rates across the WHO MONICA Project populations. Lancet, 355:675-687.

LEVY, R. I., 1981. The decline in cardiovascular diseases mortality. Annual Review of Public Health, 2:49-70.

LINDBERG, G.; GULLBERG, B. \& ECKLUND, G. A., 1992. Serum sialic acid concentration predicts both coronary heart disease and stroke mortality: Multivariate analysis including 54,385 men and women during 20.5 years follow-up. International Journal of Epidemiology, 21:253-257.

LORBER, B., 1996. Are all diseases infectious? Annals of Internal Medicine, 125:844-851.

MCKINLAY, J. B.; MCKINLAY, S. M. \& BEAGLEHOLE, R., 1989. A review of the evidence concerning the impact of medical measures on recent mortality and morbidity in the United States. International Journal of Health Services, 19:181-208.

METHA, J. L.; SALDEEN, T. G. P. \& RAND, K., 1998. Interactive role of infection, inflammation and traditional risk factors in atherosclerosis and coronary artery disease. Journal of the American College of Cardiology, 31:1217-1225.

MIZGALA, H. F. \& SCHULZER, M., 2000. Coronary events and coronary care: MONICA project. Lancet, 356:430-431.

MOZAR, H. N.; BAL, D. G. \& FARAG, S. A., 1990. The natural history of atherosclerosis: An ecologic perspective. Atherosclerosis, 82:157-164.

NCHS (National Center for Health Statistics), 1990. Vital Statistics of the United States, Vol. II, “Mortality". Published and Unpublished Data - Select- 
ed Years. Washington, DC: Public Health Services.

NIETO, F. J., 1998. Infections and atherosclerosis: New clues for an old hypothesis? American Journal of Epidemiology, 148:973-948.

OSEASOHN, R.; ADELSON, L. \& KAJI, M., 1959. Clinicopathologic study of thirty-three fatal cases of Asian influenza. New England Journal of Medicine, 260:509-518.

PLESKOV, V. M.; BANNIKOV, A. I. \& ZAITZEV, I. V., 1994. The receptor-mediated endocytosis of influenza viruses and low-density lipoproteins by tissue cells. Voprosy Virusologii, 39:121-125.

RAVENHOLDT, R. T., 1966. Historical epidemiology and grid analysis of epidemiologic data. American Journal of Public Health, 52:776-790.

REINERT-AZAMBUJA, M., 1994. 1918-19 influenza pandemic and ischemic heart disease epidemic: Cause and effect? Atherosclerosis, 109:328.

RIDKER, P. M.; CUSHMAN, M.; STAMPFER, M. J .; TRACY, R. P. \& HENNEKENS, C. H., 1997. Inflammation, aspirin and the risk of cardiovascular disease in apparently healthy men. New England Journal of Medicine, 336:973-979.

ROSAMOND, W. D.; CHAMBLESS, L. E.; FOLSOM , A. R.; COOPER, L. S.; CONWILL, D. E.; CLEGG, L.; WANG, C. H. \& HEISS, G., 1998. Trends in the incidence of myocardial infarction and in mortality due to coronary heart disease, 1987 to 1994 . New England Journal of Medicine, 339:861-735.

ROSS, R. \& GLOMSET, J. A., 1976a. The pathogenesis of atherosclerosis. New England Journal of Medicine, 295:369-377.

ROSS, R. \& GLOMSET, J. A., 1976b. The pathogenesis of atherosclerosis. New England Journal of Medicine, 295:420-425.

ROSS, R., 1999. Atherosclerosis: An inflammatory disease. New England Journal of Medicine, 340:115126

SCHMITZ, G.; HERR, A. S. \& ROTHE, G., 1998. T-Iymphocytes and monocytes in atherogenesis. Herz, 23:168-177.

SISCOVICK, D. S.; RAGHUNATHAN, T. E.; LIN, D.; WEINMANN, S.; ARBOGAST, P.; LEMAITRE, R. N.; PSATY, B. M.; ALEXANDER, R. \& COBB, L. A., 2000. Influenza vaccination and the risk of primary cardiac arrest. American Journal of Epidemiology, 152:674-677.

STALLONES, R. A., 1980. The rise and fall in ischemic heart disease. Scientific American, 243:43-49.

STEINBERG, D. \& WITZUM , J. L., 1990. Lipoproteins and atherogenesis. JAMA, 264:3047-3052.
SYDENSTRICKER, E., 1931. The incidence of influenza among persons of different economic status during the epidemic of 1918. Public Health Reports, 46:154-170.

SYTKOWSKI, P. A.; D'AGOSTINO, R. B.; BELANGER, A. \& KANNEL, W. B., 1996. Sex and time trends in cardiovascular disease incidence and mortality: The Framingham Heart Study. American Journal of Epidemiology, 143:338-350.

TAUBES, G., 2001. The soft science of dietary fat. Science, 291:2536-2545.

US BUREAU OF THE CENSUS, 1954. Estimates of the United States population and of the components of change, by age, color and sex: 1940-1950. Current Population Reports, Series P-25, 98:6-8.

US BUREAU OF THE CENSUS, 1955. Estimates of the population of the United States by age, color and sex: 1900-1940. Current Population Reports, Series $\mathrm{P}-25,114: 4-11$.

VELICAN, D.; SERBAN-PIRIU, G.; PETRESCU, C. \& VELICAN, C., 1989. Prevalence of thick intimas and of obstructive lesions in the vessels supplying the conduction system of the heart. Medicine Interne, 27:197-208.

VISSEREN, F. L.; VERKERK, M. S.; BOUTER, K. P.; DIEPERSLOOT, R. J . \& ERKELENS, D. W., 1999. Interleukin- 6 production by endothelial cells after infection with influenza virus and cytomegalovirus. Journal of Laboratory and Clinical Medicine, 134:623-630.

WATANABE, T: HARAOKA, S. \& SHIMOKAMA, T. 1996. Inflammatory and immunological nature of atherosclerosis. International Journal of Cardiology, 54(Sup.):S51-S60.

WING, S. B.; BARNETT, E. M.; CASPER, M. L. \& TYROLER, H. A., 1992. Geographic and socioeconomic variation in the onset of decline of ischemic heart disease mortality in the United States. American Journal of Public Health, 82:204-209.

WING, S. B.; HAYES, C.; HEISS, G.; JOHN, E.; KNOWLES, M.; RIGGAN, W. \& TYROLER, H. A. 1986. Geographic variation in the onset of the decline of ischemic heart disease mortality in the United States. American Journal of Public Health, 76:1404-1408.

ZHU, J.; NIETO, F. J.; HORNE, B. D.; ANDERSON, J. L.; MUHLESTEIN, J. B. \& EPSTEIN, S. E., 2001. Prospective study of pathogen burden and risk of myocardial infarction or death. Circulation, 103: 45-51. 


\section{Debate on the paper by Maria Inês} Reinert Azambuja \& Bruce B. Duncan

\author{
Debate sobre o artigo de Maria Inês
}

Reinert Azambuja \& Bruce B. Duncan

\section{Rosely Sichieri}

Instituto de Medicina Social, Universidade do Estado do Rio de Janeiro, Rio de Janeiro, Brasil.
The article by Azambuja \& Duncan is a stimulus for rethinking cardiovascular disease (CVD) epidemiology. As the authors acknowledged, many individuals with atherosclerosis, a major component of the causal pathway for CVD, lack identifiable traditional risk factors. This is a reasonable argument for searching for other potential etiologies, and a potential infectious risk factor has recently gained strong support.

The authors presented ecological evidence of an association between coronary heart disease mortality and influenza infection. If true, prevention of CVD could be substantially changed. However, as the authors stated, ecological analysis may have many flaws and epidemiological data lack robustness due to the many possible confounding factors. Thus, socioeconomic level is an important risk factor for CVD and also a strong potential confounder for the association between coronary heart disease mortality and influenza infection. Interestingly, as mentioned by Azambuja \& Duncan, the high mortality rate from influenza in whites as compared to blacks suggests that socioeconomic confounding factors are not the main explanation for the association. On the other hand, age-adjusted mortality rates from coronary heart disease (CHD) in Minnesota for the years 1960-1978 showed that influenza and pneumonia death rates were unrelated to CHD trends (Gillum et al., 1984).

Another important confounding factor is smoking. Cigarette smoking is associated with differences in the incidence and severity of a broad array of respiratory illnesses, ranging from the common cold to cancer. In addition, while the general effect of smoking on respiratory diseases is adverse, in the case of hypersensitivity pneumonitis, smoking may actually be associated with a decrease in the incidence. Therefore, smoking can modify the association between CHD and influenza infection in a complex way.

It should also be noted that CHD is not the first condition to be described by a multifactorial design that includes infection as one of the important factors. Other non-communicable chronic conditions such as hepatic cancer, dyspepsia, and gastric cancer have also been asso- ciated with specific microorganisms. In relation to cardiovascular diseases, several studies have shown Chlamydia pneumoniae, Heliobacter pylori, and herpes simplex virus infections as risk factors for the atherogenic process. Nevertheless, a role for microorganisms in the etiology of CHD has gained support by the understanding that the final occlusion of the vessel in atherosclerosis results from a combined effect of the plaque and inflammatory process, when infection of the endothelial cells may play a decisive role. According to these findings, new risk factors adding to the predictive value of old ones such as high body mass index, smoking, serum lipids, and sedentary life style, are markers of the inflammatory process. Thus, C-reactive protein, a non-specific inflammation marker, is an excellent predictor of $\mathrm{CHD}$ and stroke.

Infection can also be considered a potential effect modifier of traditional CVD risk. Azambuja \& Duncan discuss that the risk of CVD associated with fat/cholesterol intake may depend on prior influenza infection. Other findings have supported this hypothesis, and it has been suggested that physical activity, smoking, and lipids can modulate immune status and thus susceptibility to infections that are potentially important in atherogenesis (O'Connor, 2001).

The importance of this nascent field associating chronic diseases with infections was recently highlighted in a symposium that critically examined the role of infectious agents in ulcer, cancer, obesity, atherosclerosis, and diabetes (Dhurandhar, 2001). However, to establish a causal link between infection and any chronic disease is a difficult task, because the presence of microorganisms may be undetectable by the time the disease is diagnosed, and the presence of antibodies does not establish a causal relationship. These methodological constraints were overcame in the case of the association between gastric cancer and $\mathrm{H}$. pylori. The association was first suggested in the 1980s and is now well accepted, allowing the prevention of this chronic disease by antimicrobial agents. A similar therapeutic approach has been discussed for CVD prevention, but an inappropriate therapy for such highly prevalent diseases could lead to resistance in both targeted and non-targeted organisms (O'Connor et al., 2001). In conclusion, many new preventive strategies and treatment options could be developed if this infectious pathway proves to be true for CVD.

DHURANDHAR, N. V., 2001. Chronic nutritional diseases of infectious origin: An assessment of a 
nascent field. Journal of Nutrition, 131:2787-2810.

GILLUM, R. F.; JACOBS Jr., D. R.; LUEPKER, R. V.; PRINEAS, R. J.; HANNAN, P.; BAXTER, J.; GOMEZMARIN, O.; KOTTKE, T. E. \& BLACKBURN, H., 1984. Cardiovascular mortality trends in Minnesota, 1960-1978. The Minnesota Heart Survey. Journal of Chronic Diseases, 37:301-309.

O'CONNOR, S.; TAYLOR, C.; CAM PBELL, L. A.; EPSTEIN, S. \& LIBBY, P., 2001. Potential infectious etiologies of atherosclerosis: A multifactorial perspective. Emerging Infectious Disease, 7:780-788.

\section{Marcelo Urbano Ferreira}

Departamento de

Parasitologia, Instituto de Ciências Biomédicas

Universidade de São Paulo, São Paulo, Brasil

\section{Association between influenza and coronary heart disease: how convincing is available evidence?}

The first report of a temporal association between influenza epidemics and mortality from coronary heart disease (CHD) was published by British epidemiologists in 1978. However, the authors state that they "could not hope to provide clear-cut evidence of a causal relationship, nor the sequence of the two conditions" from their data (Bainton et al., 1978:238-239).

The old hypothesis that chronic inflammation and infection are involved in the pathogenesis of atherosclerosis and CHD has been revived in the 1980s and 1990s (Javier Nieto, 1998). Much of the current research has been stimulated by the finding that CHD patients more frequently present antibodies to pathogens such as Chlamydia pneumoniae, cytomegalovirus, and Helicobacter pylori, as well as serum markers of inflammation, than population controls (Muhlestein, 2001). Moreover, Chlamydia is frequently detected in atherosclerotic plaques of coronary arteries in CHD patients and induces atherosclerotic lesions in experimental models (Grayston, 2000). Evidence suggesting that this pathogen is involved in all stages of CHD is available. Chronic Chlamydia infections are associated with lymphoproliferative inflammatory responses characterizing the early stages of atherosclerosis, with changes in the lipid metabolism that may accelerate plaque formation, and with intra-plaque inflammation leading to plaque rupture and artery occlusion.

If a strong and plausible association between Chlamydia infection and CHD has been found, why should we look for other infections putatively associated with CHD? For at least two reasons: (a) when a careful adjustment for potential confounders (including socioeconomic factors) is made, the statistical association between the presence of anti-Chlamydia antibodies and CHD becomes rather weak (Danesh et al., 2000b), and (b) the positive association between low-grade chronic inflammation and CHD is unrelated to the presence of antibodies to Chlamydia or H. pylori (Danesh et al., 2000a). These findings suggest that other pathogens to which patients have been exposed, or their "pathogen burden", may be associated with chronic inflammation and CHD (Javier Nieto, 1998; Zhu et al., 2001). Here Azambuja \& Duncan report an association between prior exposure to influenza and CHD mortality in the United States.

The ecological design represents a major limitation of the study by Azambuja \& Duncan, since we cannot compare the exposure to several known risk factors for $\mathrm{CHD}$ and respiratory infections (including socioeconomic variables) in affected and non-affected subjects. The specificity (in the sense used by Bradford $\mathrm{Hill}$ ) of a putative causal association between $\mathrm{H} 1 \mathrm{~N} 1$ influenza virus infection and CHD is disputable. We can hypothesize, for example, that a proportion of subjects infected with influenza virus during major epidemics are also more susceptible to other respiratory tract infections, including Chlamydia, perhaps because many of them are current or past smokers. In this example, therefore, Chlamydia infection and smoking represent major potential confounding factors that should be controlled for. Furthermore, the decline of CHD mortality over the last third of the twentieth century has alternatively been interpreted as a late consequence of the introduction of antibiotics, some of them active against Chlamydia, two to three decades earlier (Javier Nieto, 1998).

The biological plausibility of the etiologic association between influenza virus infection and CHD deserves further discussion. CHD pathogenesis has been associated with chronic inflammation caused by persistent Chlamydia, $\mathrm{H}$. pylori, and cytomegalovirus infections (Muhlestein, 2001), but not by acute infections. Furthermore, in contrast with Chlamydia and cytomegalovirus, influenza A virus infection rarely involves the myocardium, the pericardium, or the vascular endothelium. The alternative hypothesis that a systemic, rather than local, inflammatory or autoimmune mechanism leads to plaque formation in influenza infection, proposed by Azambuja \& Duncan, is insightful, but lacks further experimental support. On the other hand, the finding that influenza virus induces platelet aggregation, cit- 
ed by Bainton et al. (1978) as a possible link between influenza and myocardial infarction, could be explored using modern epidemiological and experimental methods.

After an absence of 21 years, $\mathrm{H} 1 \mathrm{~N} 1$ viruses reappeared in the United States in 1977, infecting mostly college-aged individuals. It would be interesting to follow the incidence of CHDassociated events in this cohort of exposed subjects to confirm (or rule out) the association found by Azambuja \& Duncan. Moreover, the availability of vaccines and amantadine or rimantadine prophylaxis provides the basis for clinical trials to address this topic.

BAINTON, D.; JONES, G. R. \& HOLE, D., 1978. Influenza and ischaemic heart disease - A possible trigger for acute myocardial infarction? International Journal of Epidemiology, 7:231-239.

DANESH, J.; WHINCUP, P.; WALKER, M.; LENNON, L.; THOMPSON, A.; APPLEBY, P.; GALLIMORE, J. R. \& PEPYS, M. B., 2000a. Low grade inflammation and coronary heart disease: Prospective study and updated meta-analyses. BMJ, 321:199-204.

DANESH, J.; WHINCUP, P.; WALKER, M.; LENNON, L.; THOMPSON, A.; APPLEBY, P.; WONG, Y. K.; BERNARDES-SILVA, M. \& WARD, M., 2000b. Chlamydia pneumoniae IgG titres and coronary heart disease: Prospective study and meta-analysis. BMJ, 321:208-213.

GRAYSTON, J. T., 2000. Background and current knowledge of Chlamydia pneumoniae and atherosclerosis. Journal of Infectious Diseases, 181(Sup. 3):S402-S410.

JAVIER NIETO, F., 1998. Infections and atherosclerosis: New clues from an old hypothesis? American Journal of Epidemiology, 148:937-948.

MUHLESTEIN, J. B., 2001. Chronic infection and coronary heart disease. Medical Clinics of North America, 84:123-148.

ZHU, J.; JAVIER NIETO, F.; HORNE, B. D.; ANDERSON, J. L.; MUHLESTEIN, J. B. \& EPSTEIN, S. E., 2001. Prospective study of pathogen burden and risk of myocardial infarction or death. Circulation, 103:45-51.
Guilherme L. Werneck

Pós-Graduação em Saúde Coletiva, Núcleo de Estudos de Saúde Coletiva, Universidade Federal do Rio deJaneiro, Rio de Janeiro, Brasil.
In their insightful paper, Maria Inês Azambuja \& Bruce Duncan consider the possibility that, at least in part, the pathogen burden of H1N 1 influenza infection might have been an important determinant in the rise and fall of coronary heart disease (CHD) mortality observed in the 20th century. Although I consider the paper well-founded, with plausible arguments, the empirical evidence is not very convincing to me. My comments are general thoughts that may hopefully contribute to the design of new studies on the topic, which I agree is important and deserves further consideration.

The authors drawn on two major pieces of empirical evidence to supporting their hypothesis: (1) the similarity between the relative mortality associated with the 1918-1919 influenza pandemic and the distribution of CHD deaths in the period 1920-1985, across successive birth cohorts; and (2) the ecological association between an indirect measure of longer persistence of HIN 1 influenza virus and delayed onset of decline in CHD death rates.

Concerning the first piece of empirical evidence, at least two questions might be raised:

- Part of the "drop" in CHD mortality that we see in the graph is actually derived from the fact that more recent cohorts have not actually finished evolving over time. Therefore, there are successive missing bars of mortality for the older ages in the more recent cohorts, which, if included, would make the decline less sharp.

- It does not seem to me that the increase in CHD mortality among younger individuals, which really appears to "follow" the influenza pandemic mortality, tends to return to the levels expected for a population not exposed to the burden of influenza.

Regarding the second piece of evidence, the ecological correlation is based only on nine areas, at least one of which may be an extreme observation. To get a feeling of the uncertainty underlying the data, we approximated the values by inspecting the graph, and performed a simple exercise of estimating a series of Spearman correlation coefficients for random samples of the data (with replacement, using bootstrap): in more than $40 \%$ of the samples, the Spearman correlation coefficient was not statistically significant at the 0.05 level.

I wish to congratulate the authors for sharing their provocative thoughts with us. If more robust evidence could be gathered, they might provide important clues regarding CHD epidemiology and be useful for public health purposes. 
Euclides A. Castilho $\&$ Nelson Gouveia

Departamento de Medicina Preventiva, Faculdade de Medicina, Universidade de São Paulo, São Paulo, Brasil .

\section{Biological (anti)terrorism by mother nature?}

Numerous attempts have been made to explain the time-trend patterns in coronary heart disease (CHD) mortality in America and Europe over the last century. The question as to why CHD mortality rose steadily until approximately mid-century and then began to decline has been intriguing investigators for a long time, and a series of possible explanations for such a pattern have been described. In their article, Azambuja $\&$ Duncan introduce another interesting hypothesis seeking to explain the rise and fall in CHD.

Focusing on events in the United States, the authors argue that the time-trend pattern in CHD mortality can be explained by the influenza epidemic striking that country during the first half of the 20th century. The infection, they explain, could have changed individual susceptibility to other known risk factors for $\mathrm{CHD}$, leading to increased mortality among the exposed. Since the flu epidemic was restricted to certain time periods, new generations of unexposed individuals were then responsible for the later decline in CHD mortality.

It is interesting to note the growing interest in infectious disease theories for many of the most common degenerative diseases of our times. For some specific cancers, for example, established mechanisms have already linked the diseases to various infectious agents. Some even claim that every disease has an infectious "cause", an argument that has been disputed by others that affirm that most "causes" are "environmental".

Without going into each theory's pros and cons, which is beyond the scope of this article, it is interesting to note that some infectious agents such as Chlamydia pneumoniae and cytomegalovirus have already been associated with coronary and peripheral arterial diseases. In addition, it is known that influenza epidemics are associated with excess morbidity and mortality, not only from respiratory diseases but also from other causes.

Nevertheless, the contribution of influenza to clinical events, including clinical cardiovascular diseases, is frequently not recognized (Siscovick et al., 2000). We identified some articles in this respect showing associations between influenza vaccination and both reduced risk of primary cardiac arrest (Siscovick et al., 2000) and reduced mortality from influenza among older persons (Reichert et al., 2001).

However, the main argument of Azambuja's $\&$ Duncan's theory is built upon data from influenza and pneumonia mortality (a marker for influenza activity). It is conceived that about 99\% of mortality classified as due to pneumonia and influenza are in fact due to pneumonia, clearly not all associated with primary influenza virus infection. The sources of the data they used are from death certificates and hospital discharge diagnoses. Both probably underestimate the impact of influenza, but using pneumonia and influenza can overestimate the impact of influenza as well.

Moreover, they state that the epidemic affected whites and males most heavily, which were also the main groups hit by the rise in CHD mortality in the US. However, one can argue that if the pandemic had hit these groups the hardest, survivors of the pandemic, that is, the ones "primed" by the infection to predispose them to future development of CHD, would more likely be blacks and women.

In addition, influenza A (HIN1) circulated in human populations from 1918 (the great pandemic) to 1956, and reemerged about 19761977. The authors do not discuss, at least not very clearly, what happened to CHD in the period from 1956 to 1976, when H1N1 was not circulating in humans. Also, they do not propose any association between coronary cardiac diseases since H3N 2 emerged in 1968 until the present.

Borrowing Hill's criteria for assessing "causality" to illustrate this commentary, we observed that the Authors provided a series of clinicalpathological and biomolecular clues to reinforce their argument, thus presenting biological credibility or plausi bility for their findings. However, this is one of the most criticized criteria in the epidemiological literature, given that biological mechanisms can easily be elaborated linking an exposure to an outcome. If the epidemiological evidence pointed exactly in the opposite direction it would not be difficult to find another biological explanation.

As far as the strength of the association is concerned, the authors consider a Spearman correlation $=-0.68$ with a descriptive level of significance $=0.042$ as being a NOTABLE (our capitals) negative correlation. It should be noted that with nine observations, they had only seven observations to contribute to the calculation of the residual in the estimated linear equation, and particularly that taking into account an R2 $=0.46(-0.682)$, which means low precision, they do lacked sufficient evidence to consider correlation notable.

The essential temporal relation criterion is clear in their analysis of birth cohorts, but another important criterion that could be investigated is the consistency of findings. During 1918-1919, influenza was pandemic, since it affected most countries in the world. In Brazil, 
there are reports of more than 300,000 excess deaths attributed to the flu epidemic. The same occurred in European countries, where historical data are usually available. Thus, it would be interesting to replicate similar analysis to data from other countries to learn whether a similar pattern of CHD mortality across birth cohorts, in accordance with mortality from influenza in the same cohorts, corroborate their study's findings.

Finally, as the authors made clear, the study presented here is a correlational one with the clear purpose of raising new hypotheses to be further evaluated using different epidemiological designs. According to Hennekens \& Buring (1987), the chief limitation of such studies is their inability to link exposure to diseases in particular individuals, in other words, correlation data represent average exposure levels rather than individual values. Thus, it could be that individuals unexposed to the influenza virus were the ones who later died of CHD, that is, the so-called ecological fallacy. A second major limitation of correlational studies, as recognized by the Authors, is the inability to control for the effects of potential confounding factors.

Notwithstanding such consi derable limitations, Azambuja \& Duncan were brave in facing the challenge of introducing a new pioneering theory.

As such, it is worth quoting Andrew J. Hall (2001:1197-1198), commenting on another pioneering article: “the study illustrates another saying of Geoffrey Rose: an epidemiologist needs dirty hands and a clean mind". Dirty hands from collecting all of the confounding variables, influenza, and CHD data, and clean minds with which to judge the evidence.

\section{Acknowledgments}

We thank Tim Uyeki (Centers for Disease Control and Prevention/ National Center for Infectious Diseases/ Epidemiology Section/Influenza Branch) for comments and provision of influenza data in the United States, and for advice in literature searches on influenza vaccination effects.

HALL, A. J., 2001. Ecological studies and debate on rotavirus vaccine and intussusception. Lancet, 358:1197-1198.

HENNEKENS, C. H. \& BURING, J. E., 1987. Epidemiology in Medicine. Boston: Little, Brown \& Company.

REICHERT, T. A.; SUGAYA, N.; FEDSON, D. S.; GLEZEN, W. P.; SIMONSEN, L. \& TASHIRO, M., 2001. The Japanese experience with vaccinating schoolchildren against influenza. New England Journal of Medicine, 344:889-896.

SISCOVICK, D. S.; RAGHUNATHAN, T. E.; LIN, D.; WEINMANN, S.; ARBOGAST, P.; LEMAITRE, R. N.; PSATY, B. M.; ALEXANDER, R. \& COBB, L. A., 2000. Influenza vaccination and the risk of primary cardiac arrest. American Journal of Epidemiology, 152:674-677.

\section{The authors reply}

Os autores respondem

Maria Inês Reinert Azambuja \& Bruce B. Duncan

\section{Capturing determinants of vulnerability from modifications in disease occurrence}

"In science, just as in art and in life, only that which is true to culture is true to nature" (Luwdick Fleck, 1979:35).

"Once we recognize that state of the art is a social product, we are freer to look critically at the agenda of our science, its conceptual framework, and accepted methodologies, and to make consci ous research choices" (Richard Levins \& Richard Lewontin, 1987, apud Krieger, 2001:668).

First of all, we wish to thank Cadernos de Saúde Pública/Reports in Public Health (CSP) for the opportunity to publish this paper. It presents a nearly 10-year-old hypothesis (Reinert-Azambuja, 1994) of an association between the 1918 influenza pandemic and the rise and fall in CHD mortality registered in the 20th century, which, prior to its submission to the CSP, had found no room in scientific journals.

During this period, we witnessed the emergence of inflammation as the best synthesis of accumulated knowledge about the morphological and biochemical characteristics of atherosclerotic plaques (Ross, 1993) and a substitution of inflammation for degeneration as the main pathogenic process leading to several additional common chronic diseases (Lorber, 1996).

Transitions in paradigms have implications for epidemiology (Pearce, 1996; Silva, 1990). As we know, the degenerative paradigm did more than target lifestyle-related exposures as potential risk factors for CHD. It also coherently targeted the individual as the most adequate observation unit for studying those exposures and their effects. For epidemiological research, this meant a huge investment in individualcentered epidemiological studies and a proportional abandonment of traditional, more society-oriented approaches to the understanding of causes of disease occurrence in populations (Pearce, 1996; Silva, 1990; Susser \& Bresnahan, 2001). This trend now appears to be changing: "epidemiology is in transition from a science that identifies risk factors for disease to one that analyzes thesystems that generate patterns of disease in populations" (Koopman, 1996:630). 
We believe that the Editors' sensitivity towards a growing debate on the adequacy of current epidemiological methods and objects of study (Barata, 1997; Koopman, 1996; Kriegger, 2001; Levins \& Lopez, 1999; Pearce, 1996; Susser \& Bresnahan, 2001; Susser \& Susser, 1996; Weed, 2001) has contributed to their allocation of this space in the CSP for the publication and discussion of our paper. We wish to thank Drs. Rosely Sichieri, Marcelo Urbano Ferreira, Guilherme Werneck, and Euclides Castilho \& Nelson Gouveia for reviewing and commenting on our work. We hope that our reply to these critiques might be read as once instructed by Bacon, “....not to contradict, nor to believe, but to weigh and consider" (1597, apud, Miettinen, 2001:592).

To answer some of the doubts and objections they have raised, we would begin by taking a step back and emphasizing two points that are central to the discussion but - given the still dominant role of individual-centered epidemiologic reasoning - may have remained partially misunderstood.

The first point is that the hypothesis set forth in our paper refers to an association between two occurrences. We do not expect this association to immediately translate to the individual level. We never stated that influenza infection "caused" the individual cases of CHD recorded in the United States. What we said was that the influenza pandemic of 1918 (and the frequent smaller influenza epidemics following it until 1957) might have been responsible for the emergence (and shape) of the CHD epidemic curve observed during the 20th century. Such a difference may appear senseless at first sight. However, we must remember what was once said by Reuel Stallones (1980) and Geophrey Rose (1985): causes of cases are not necessarily the same as causes of case distributions in the population.

A case is an entity, an epidemic is a process. To understand the emergence and development of an epidemic one must focus on variations. Such variations in occurrence depend not only on correlated variations in "exposures" to specific "risk factors" for individual cases, but also, and perhaps principally, on variation in the proportion of "vulnerable" exposed individuals in the population, meaning a qualitative modification in the denominator of the occurrence equation according to time, person, and place.

Ecological studies attempt to answer not what caused disease in individuals nor even what caused a given rate of disease in a specific population, but raise plausible hypotheses as to what caused differences in rates over time, or across geographic areas. Differences in rates may be modeled as resulting both from relative differences in population exposures and relative differences in the average population vulnerability to those exposures. This vulnerability occurs at the individual level and might be considered an individual "risk factor" if its pathophysiological mechanisms were better understood and we had the means to measure its value in individuals. Until such conditions are met it can only be captured as it expresses itself, as a relative variation in disease rates over time or among populations, independently of variation in other known environmental exposures.

The hypothesis set forth in our paper might be read as follows: the HIN 1 influenza "priming" was responsible for the emergence and distribution of differential acquired vulnerability to CHD among the US population; the total burden of the CHD epidemic was the result of the interaction between that differential vulnerability and other CHD-related environmental exposures (other infections, Western-style diet, smoking...) over time.

As we do not believe that the individual level of analysis is the most appropriate to explore the cause of the CHD epidemic and have made no attempt to directly infer CHD causation in individuals from an association between two distributions detected at the population level, we understand, as do other authors (Pearce, 1996; Szklo \& Nieto, 2000) that objections based on the ecological fallacy do not apply to this case.

The second point is that according to the hypothesis, the 1918 influenza pandemic (and small influenza epidemics following it until 1957), and still more specifically, its effect on particularly vulnerable (young, white, male) members of the population, "initiated" the CHD epidemic which emerged in 1925 and begun to remit in the late 1960s.

This is completely different from saying, as do several individual-centered epidemiological studies, that infection may have a role as "precipitator" of acute myocardial infarction or CHD death. Again, the hypothesis refers to the cause of the epidemic. Of course, according to current biological knowledge, if the proposed association is true, reinfection of an individual "initiated" by influenza virus, or even by another infectious agent sharing cross-reacting antigens with it (Wucherpfennig \& Strominger, 1995), among other factors, might "preci pitate" MI or CHD death. But what we wish to emphasize is a possible role of infection in the emergence (and shape) of the CHD epidemic phenomenon. 
Having discussed these two points, and, we expect, adequately answered comments related to them, we will attempt to answer the specific comments of each author.

Rosely Sichieri suggested the possibility of confounding by other variables like socioeconomic status (SES) and smoking. The association between SES and CHD mortality appears to have varied over time. Apparently, during the rise in CHD mortality there was an association between CHD and high SES. During the decline, CHD was found mostly among low SES groups (Wing, 1988). Infectious disease occurrence is highly related to SES. However, SES differences are probably less relevant during major epidemics. From 25 to $40 \%$ of the American population became recognizably ill during the pandemic. Serological surveys in the 1960s showed seroprevalences of anti-Hsw antibodies (reactive to pandemic-related strains of influenza virus) equal to or greater than $80 \%$ in cohorts born between 1888 and 1919 (Dowdle, 1999). More interestingly, as we mentioned, severe effects of influenza infection in 1918-1919 appear to have occurred mostly among the healthiest people in the nation, as evidenced by high mortality and morbidity among highly selected American soldiers (Crosby, 1989). One would expect the effect of SES on vulnerability to influenza infection to be greater after the peak in the pandemic, which could at least partially explain a similar transition in vulnerability to CHD to lower SES groups among later birth cohorts. Cohorts born after 1900 would hypothetically have been "primed" by influenza viruses during the smaller epidemics occurring from 1920-1957, after they had reached their twenties, the age at which, if this hypothesis is correct, the greatest priming would occur.

The fact that cardiovascular mortality trends in Minnesota from 1960 to 1978 (Gillum et al., 1984) were not explained by concurrent influenza epidemics cannot be taken as an argument against our paper's hypothesis. What we contended was that CHD mortality trends observed during and after the 1960s were probably dependent on the evolution of influenza epidemics occurring several decades before (when "priming" to future CHD development would have occurred). On the other hand, the increase in CHD mortality rates during the 1967-1968 influenza epidemic is evident in Figure 4 of Gillum's paper (and could be due to immune-inflammatory flares occurring in influenza- "primed" individuals upon reinfection).

Regarding smoking, the only way to consider it a confounder of the association we propose is attributing to this recent habit the still unexplained age (sex and race) distribution of morbidity/mortality seen during the 1918-1919 influenza pandemic - considered in our paper as a "proxy" for the distribution of CHD "priming" on influenza infection - or at least to show that the distribution of smoking among cohorts is correlated with this age/ sex/ race distribution. That would be an interesting possibility. Tobacco use greatly increased at the end of the nineteenth century, following the invention of the cigarette-rolling machine (1884) and the rise of mass consumer marketing (Proctor, 2001). Virtually an entire generation of men returned from World War I addicted to cigarettes (Proctor, 2001). However, very few women smoked at the turn of the century, because smoking was seen as immoral and a sign of bad character (Herrera, 1999). Until the late 1920s, tobacco companies feared advertising for women. More widespread cigarette smoking by women did not occur until the 1930s (Herrera, 1999). Since the age pattern of pandemic-related influenza deaths was not restricted to men, we could not attribute it to smoking. But if cigarette smoking was probably not the most important determinant of young adult morbidity and case-fatality in 1918-1919, the WWI addicted were mostly from the same birth cohorts of men who, we propose, were "primed" to CHD during the pandemic. Smoking by women, on the other hand, attained significance only in cohorts born after 1910, when the effects of influenza "priming" were fading. Smoking might thus explain the increasing sex ratios observed in CHD mortality over time, as influenza "primed" birth-cohorts (1880-1915) grew older.

Marcelo Ferreira highlighted the paper by Bainton et al. (1978) as the first to associate the excess cardiovascular deaths occurring during influenza epidemics with an influenza triggering of myocardial infarction. The suggestion of platelet aggregation by Bainton et al. (1978) (and of increased fibrinogen and factor VII levels by Woodhouse et al., 1994) as a link between respiratory (re?)-infection and myocardial infarction is probably part of the truth, either at a mechanistic level or as markers of an activated inflammatory process. But these acute phenomena cannot explain the continuing increase in the proportion of deaths attributed to organic heart diseases during successive influenza epidemics. As described in our paper, cardiovascular deaths increased from $1.6 \%$ in the 1918 pandemic (Collins, 1932) to 51\% in 1957-1960 (Eickoff et al., 1961), accompanying the 1880-1915 birth cohorts in their trajectory towards the middle third of the 20th century. 
As recalled by Ferreira, the resumption of interest in the infectious hypothesis for CHD occurred in the wake of the identification of Chlamydia pneumoniae, reported in 1986 (Grayston et al., 1986). Initial reports of a possible association between chronic Chlamydia infection and CHD were published in 19881989 (Richer, 1989; Saikku et al., 1988). But it was not until the late 1990s, when the inflammatory paradigm became predominant in the pathophysiological explanation of atherogenesis, that infection was seriously considered as a possible cause of CHD. In 1998, for the first time two seminars were devoted to this issue, one in Europe and the other in the United States. However, expectations regarding the definitive implication of Chlamydia pneumoniae (or any other infectious agent) in atherogenesis have yet to be fulfilled. More rigorous designs apparently weakened the seroepidemiological links between Chlamydia infection and atherosclerosis (O'Connor et al., 2001). N onetheless, considerable evidence exists to support the hypothesis that infection may be involved in atherosclerotic disease (O'Connor et al., 2001). At present, the specific effects of antibiotic treatment remain unclear, and results of prospective randomized clinical trials are awaited, but they are not expected to provide convincing evidence for a causal relationship between Chlamydia infection and atherosclerosis (O'Connor et al., 2001). This difficulty in establishing an infectious etiology has resulted in two current trends in relation to the role of infection in atherosclerosis: (1) the attribution of a pathogenic role not to one specific infectious agent, but to the infectious burden to which individuals are exposed during their lives (Espinoloa-Klein et al., 2002) and (2) the categorization of infection as merely an additional risk factor, to be integrated into the multifactorial framework of CHD causation (O'Connor et al., 2001).

The first trend does not contradict the hypothesis presented in our paper. In the case of multiple sclerosis (Wucherpfennig \& Strominger, 1995) several common pathogens (particularly from the herpesvirus, influenza, and papillomavirus families) were shown to share similar epitopes with the myelin basic protein, and each could independently initiate an autoimmune process leading to the disease. The possibility of several agents "initiating" the same condition was also advocated by Evans (1980) in discussing causes of cancer. According to both authors, this would explain why it is so hard to link the immunopathogenesis of a disease to a specific agent. Agreeing with them, we contend that an epidemic would be required to achieve that goal with respect to CHD. And none was so huge as the 1998 influenza pandemic. This is not to say that the HIN 1 influenza virus would be the only infectious agent eventually associated with CHD initiation and/ or progression. However, by the nature of the pandemic related to it, it may have been the agent best suited for disclosure through an ecological methodology.

As for the second trend - the consideration of infection merely as an additional risk factor to be incorporated into multivariate $\mathrm{CHD}$ causation models - such a stance risks missing those determinants that, as discussed above, could be suggested only upon variation in disease rates detected by population-level studies.

Agreeing with Ferreira, it would be very interesting to monitor CHD incidence among those affected by $\mathrm{H} 1 \mathrm{~N} 1$ viruses after they reappeared in 1977. Russia, a country recently experiencing dramatically increasing CHD mortality rates (Notzon et al., 1998), underwent a documented 14-year period (1977-1991) of epidemic H1N 1 influenza virus activity (Kiselev et al., 1994). Yet we must be cautious. As we attempted to show in the our paper, what correlates well with the observed rise in CHD mortality is not the plain occurrence of $\mathrm{HIN} 1$ infection, but instead the occurrence of a severe response to infection, more common in young, white, male segments of the population, and which remains unexplained to date.

GuilhermeWerneck's two observations about the evidence presented in favor of a correlation between the relative mortality associated with the influenza pandemic and the distribution of CHD deaths in the period 1920-1985 are accurate.

The first is that inclusion of CHD mortality data registered after 1985 in the figure would make the birth cohort decline less sharp (besides making the correlation during the $\mathrm{CHD}$ decline worse). True. Of course it would be convenient if the cohort distribution of 19181919 influenza and pneumonia mortality alone could predict the CHD mortality curve. In fact, it "explains" the most impressive feature of the curve: the change in direction of CHD mortality trends which occurs between cohorts born before and after the turn of the 20th century. However, in addition to the point-source exposure represented by the pandemic, to explain the right tail of the cohort distribution of CHD deaths requires incorporation of the effect of an extended period of lower levels of exposure affecting cohorts born after 1900, an exposure attributed to H1N1 epidemics following the 
huge 1918-1919 pandemic until 1957. “Priming" by those epidemics is not taken into account in the figure.

The influenza and pneumonia total death toll due to influenza epidemics occurring during the inter-pandemic period (1920-1957) practically equaled the number attributed to the pandemic $(611,000 \times 675,000)$ (Glezen, 1996). However, the characteristic age distribution of influenza and pneumonia morbidity/ mortality seen during the pandemic gradually faded out over this period in morbidity (Collins, 1944) and apparently disappeared in mortality (Glezen, 1996). Parameters for estimating the cohort distribution of influenza "priming" during those epidemics were poor. As the main impact of influenza moved west and into rural areas, the US influenza mortality surveillance system was not as well prepared to follow its trail. Influenza mortality data were collected in 95 American cities. From those, 31 were west of the Mississippi River and only 13 were west of the one-hundredth meridian, which cuts through the Dakotas, Nebraska, Kansas, Oklahoma, and Texas. Rural populations were not represented in the system (Collins, 1930). Age variation in influenza-related excess deaths occurring in those regions would remain undetected. Given these difficulties and uncertainties, we did not attempt to include such effects in the figure. If we had, we would have expected a closer correlation between both trends, even with a less sharp decline in CHD mortality resulting from the inclusion of more recent CHD mortality data.

The second observation is that the increase in mortality among younger people from more recent cohorts does not seem to return to some "original" baseline expected for those not exposed to the burden of H1N 1 influenza. This is true. But as we have mentioned previously, we are not saying that $\mathrm{H} 1 \mathrm{~N} 1$ influenza infection, or the immune response to it, directly caused all the CHD cases registered since 1920.

Regarding the low value attributed by Werneck and Castilho \& Gouveia to the correlation coefficient obtained for the association between longer persistence of H1N1 influenza and delayed onset of decline in CHD death rates, based on both the relatively small number of units of observation (nine) and on what they see as extreme values, we disagree. The observations refer to population-based data, involving huge numbers of deaths (10-year periods) and individuals at risk, making them more precise estimates of the true values. The observed correlation is corroborated by descriptive data reported in our paper regarding the geographic evolution of both occurrences. Its value is high, and we would expect it to be even higher if the surveillance system had captured the occurrence of flu-related deaths in small cities from the central and western regions and from rural areas of the country.

Castilho \& Gouveia questioned the use of the "influenza and pneumonia" category for representing deaths attributed to influenza. They believe that $99 \%$ of those deaths would be due to pneumonia not clearly associated with influenza infection. This is a valid concern. But we wish to clarify that we used only secondary influenza and pneumonia mortality data (excess death rates) reported by the US Public Health Service as occurring during sharply defined increases in mortality from acute respiratory disease (Collins, 1930), a criterion which greatly increases their association with influenza infection.

We interpreted the distribution of pandemic-related deaths as the tip of a hidden iceberg of morbidity with similar age, sex, and racial distribution (see Figure 1 of our original article). From the figure we see that case fatality (deaths/ diseased) in adulthood was less than $0.5 \%$. Thus, in our understanding, CHD would be expected to develop precisely in the same age, sex, and racial group, and not in some complementary group of women, blacks, or the like.

We disagree with the low value attributed by Castilho \& Gouveia to the attempt to integrate evidence obtained at the population level with that obtained at the clinical and biomolecular levels. Current trends in scientific research emphasize the need for theories based on multiple levels of information instead of the black box approach (Krieger, 2001; Susser \& Bresnahan, 2001).

The hypothesis presented in our paper is a good example of the importance of ecological studies, the proper choice for studying causal determinants of changes in occurrences. The role of studies which attempt to capture grouplevel variations and their possible causes is currently being rehabilitated, and rightly so (Susser \& Bresnahan, 2001; Szklo \& Nieto, 2000). What is needed now are new modeling designs capable of hierarchically integrating knowledge generated at different levels (population, individual, sub-individual) of organization (Barbosa et al., 2000; Koopman et al., 2001; Krieger, 2001; Susser \& Susser, 1996). 


\section{References}

BAINTON, D.; JONES, G. R. \& HOLE, D., 1978. Influenza and ischemic heart disease: A possible trigger for acute myocardial infarction? International Journal of Epidemiology, 7:231-239.

BARATA, R. C. B., 1997. O desafio das doenças emergentes e a revalorização da epidemiologia descritiva. Revista de Saúde Pública, 31:531-537.

BARBOSA, M. T.; BYINGTON, M. R. \& STRUCHINER, C. J., 2000. Modelos dinâmicos e redes sociais: Revisão e reflexões a respeito de sua contribuição para o entendimento da epidemia do HIV. Cadernos de Saúde Pública, 16:37-51.

COLLINS, S. D., 1930. Influenza-pneumonia mortality in a group of about 95 cities in the United States, 1920-1929. Public Health Reports, 45:361406

COLLINS, S. D., 1932. Excess mortality from causes other than influenza and pneumonia during influenza epidemics. Public Health Reports, 47: 2159-2179.

COLLINS, S. D., 1944. Age and sex incidence of influenza in the epidemic of 1943-44, with comparative data for preceding outbreaks. Public Health Reports, 59:1483-1503.

CROSBY, A. W., 1989. America's forgotten pandemic: the influenza of 1918. 1st Ed. New York: Cambridge University Press.

DOWDLE, W. R., 1999. Influenza A virus recycling revisited. Bulletin of theWorld Health Organization, 77:820-828.

EICKOFF, T. C.; SHERM AN, I. L. \& SERFLING, R. E., 1961. Observations on excess mortality associated with epidemic influenza. JAMA, 176:776-782.

ESPINOLA-KLEIN, C.; RUPPRECHT, H. J.; BLANKENBERG, S.; BICKEL, C.; KOPP, H.; RIPPIN, G.; VICTOR, A.; HAFNER, G.; SCHLUMBERGER, W. \& MEYER, J., 2002. Impact of infectious burden on extent and long-term prognosis of atherosclerosis. Circulation, 105:15-21.

EVANS, A. S., 1980. Viruses. In: Cancer Epidemiology and Prevention (D. Schottenfeld \& J. F. Fraumeni Jr., ed.), pp. 364-390, Philadel phia: W.B. Saunders.

FLECK, L., 1979. Genesis and Development of a Scientific Fact. Chicago: University of Chicago Press

GILLUM, R. F.; JACOBS J r., D. R.; LUEPKER, R. V.; PRINEAS, R. J.; HANNAN, P.; BAXTER, J.; GOMEZMARIN, O.; KOTTKE, T. E. \& BLACKBURN, H., 1984. Cardiovascular mortality trends in Minnesota, 1960-1978. The Minnesota Heart Survey. Journal of Chronic Diseases, 37:301-309.

GLEZEN, W. P., 1996. Emerging infections: Pandemic influenza. Epidemiologic Reviews, 18:64-75.

GRAYSTON, J. T.; KUO, C.; WANG, S. P. \& ALTMAN, J., 1986. A new Chlamydia psittaci strain, TWAR, isolated in acute respiratory tract infections. New England Journal of Medicine, 315:161-168.

HERRERA, C., 1999. Women's history of addiction and death. In: Action in Smoking and Health. The American Medical Women's Association. 26 February 2002 «ttp:// www.ash.org>.

KISELEV, O. I.; SOMININA, A. A. \& GRINBAUM, E. B. 1994. Influenza: Current status and epidemiologic situation. Vestnik Rossiiskoi Akademii Meditsinskikh Nauk, 9:3-7.
KOOPMAN, J. S., 1996. Comment: Emerging objectives and methods in epidemiology. American Journal of Public Health, 86:630-632.

KOOPMAN, J. S.; JACQUEZ, G. \& CHICK, S. E., 2001. New data tools for integrating discrete and continuous population modeling strategies. Annals of the New York Academy of Science, 954:268294

KRIEGER, N., 2001. Theories for social epidemiology in the 21st century: An ecosocial perspective. International Journal of Epidemiology, 30:668-677.

LEVINS, R. \& LOPEZ, C., 1999. Toward an ecosocial view of health. International Journal of Health Services, 29:261-293.

LORBER, B., 1996. Are all diseases infectious? Annals of Internal Medicine, 125:844-851.

MIETTINEN, O. S., 2001. The modern scientific physician: 2. Medical science versus scientific medicine. Canadian Medical Association Journal, 165: 591-592.

O'CONNOR, S.; TAYLOR, C.; CAM PBELL, L. A.; EPSTEIN, S. \& LIBBY, P., 2001. Potential infectious etiologies of atherosclerosis: A multifactorial perspective. Emerging Infectious Diseases, 7:780-788.

PROCTOR, R. N., 2001. Commentary: Schairer and Schöniger's forgotten tobacco epidemiology and the Nazi quest for racial purity. International Journal of Epidemiology, 30:31-34.

NOTZON, F. C.; KOMAROV, Y. M.; ERMAKOV, S. P.; SEM POS, C. T.; MARKS, J. S. \& SEM POS, E. V., 1998. Causes of declining life expectancy in Russia. JAMA, 279:793-800.

PEARCE, N., 1996. Traditional epidemiology, modern epidemiology and public health. American Journal of Public Health, 86:678-683.

REINERT-AZAMBUJA, M., 1994. 1918-19 influenza pandemic and ischemic heart disease epidemic: Cause and effect? Atherosclerosis, 109:328.

ROSE, G., 1985. Sick individuals and sick populations. International Journal of Epidemiology, 14:32-38.

ROSS, R., 1993. The pathogenesis of atherosclerosis: A perspective for the 1900s. Nature, 362:801-809.

SAIKKU, P.; LEINONEN, M.; MATTILA, K.; EKMAN, M R.; NIEMINEN, M. S.; MAKELA, P. H.; HUTTUNEN, J. K. \& VALTONEN, V., 1988. Serological evidence of an association of a novel Chlamydia, TWAR, with chronic coronary heart disease and acute myocardial infarction. Lancet, 29:983-986.

RICHER, G., 1989. Chlamydia and coronary disease. Union Medicale du Canada, 118:126-127.

SILVA, G. R., 1990. Avaliação e perspectivas da epidemiologia no Brasil. In: 1o Congresso Brasileiro de Epidemiologia. Epidemiologia e Desigualdade Social: Os Desafios do Final do Século, Anais, pp. 108-139. Rio de Janeiro: ABRASCO.

STALLONES, R. A., 1980. To advance epidemiology. Annual Review of Public Health, 1:69-82.

SUSSER, E. \& BRESNAHAN, M., 2001. Origins of epidemiology. Annals of the New York Academy of Science, 954:6-18.

SUSSER, M. \& SUSSER, E., 1996. Choosing a future for epidemiology: II. From black box to Chinese boxes and eco-epidemiology. American Journal of Public Health, 86:674-677. 
SZKLO, M. \& NIETO, F. J., 2000. Epidemiology Beyond theBasics. Gaithesburg: Aspen Publishers.

WEED, D. L., 2001. Theory and practice in epidemiology. Annals of the New York Academy of Sciences, 954:52-62.

WING, S., 1988. Social inequalities in the decline of coronary mortality. American Journal of Public Health, 78:1415-1416.

WOODHOUSE, P. R.; KHAW, K. T.; PLUM MER, M.; FOLEY, A. \& MEADE, T. W., 1994. Infections and death from cardiovascular disease. Lancet, 343: 435-439.

WUCHERPFENNIG, K. W. \& STROMINGER, J. L., 1995. Molecular mimicry in T cell-mediated autoimmunity: Viral peptides activate human T cell clones specific for myelin basic protein. Cell, 80:695-705.

Submitted on 2 August 2001

Final version resubmitted on 2 October 2001

Approved on 28 December 2001 